\title{
Intracerebral Hemorrhage in Patients with Neuromyelitis Optica: Case Report with Literature Review for Possible Pathological Association
}

\author{
Hosna Saad Elshony Abdelrahman Idris Abdulaziz Al-Ghamdi \\ Rabia Muddassir \\ Department of Neurology/Internal Medicine, Security Forces Hospital, Makkah, \\ Saudi Arabia
}

\section{Keywords}

Neuromyelitis optica $\cdot$ Intracerebral hemorrhage $\cdot$ Subarachnoid hemorrhage .

Pathophysiology

\begin{abstract}
Neuromyelitis optica (NMO) is an autoimmune demyelinating disorder of the central nervous system which is characterized by attacks of optic neuritis and transverse myelitis. An association between NMO and intracerebral hemorrhage $(\mathrm{ICH})$ has been rarely recognized, having been reported only 3 times before. Here we report on a patient with NMO who eventually developed subarachnoid hemorrhage, in order to emphasize that the association between $\mathrm{NMO}$ and $\mathrm{ICH}$ is mostly not incidental and that the pathological basis for this association should be investigated thoroughly.

(C) 2021 The Author(s)

Published by S. Karger AG, Basel
\end{abstract}

\section{Introduction}

Neuromyelitis optica (NMO) and NMO spectrum disorders (NMOSD) are inflammatory disorders of the central nervous system characterized by immune-mediated demyelination and axonal damage predominantly affecting the spinal cord and optic nerves. Currently, NMO

\begin{tabular}{ll}
\hline & Hosna Saad Elshony \\
Security Forces Hospital & Almashaer Street, Altaif road \\
& 24211 Makkah (Saudi Arabia) \\
hosna.saad28@gmail.com
\end{tabular}




\section{Case Reports in Neurology}

Case Rep Neurol 2021;13:157-165

DOI: $10.1159 / 000513644$ www.karger.com/crn

Elshony et al.: Intracerebral Hemorrhage in Patients with Neuromyelitis Optica

is considered as an independent disorder and not a variant of multiple sclerosis, as it was previously believed. Whereas multiple sclerosis is mostly a cell-mediated disorder, the pathophysiology of NMO is thought to be primarily mediated by the humoral immune system [1,2], as proved by the identification of a specific autoantibody against aquaporin 4 (AQP4).

\section{Case Description}

Our patient was a 37-year-old female who had initially been diagnosed with multiple sclerosis at the age of 16 years based on recurrent attacks of motor and sensory symptoms. At that time, she was commenced on interferon; however, it was discontinued after 3 months because of the side effects, and she remained on no maintenance therapy. Over the course of the disease, she lost her bladder control as well as vision in the left eye.

At the age of 29 years, she sought another opinion at our hospital; clinically, she had complete quadriplegia with a blind left eye. Her diagnosis was revised with repetition of laboratory testing and imaging, and she was diagnosed with NMO on the basis of positive AQP4 in her cerebrospinal fluid (CSF) as well as magnetic resonance imaging (MRI), which demonstrated atrophy of the cervical cord (Fig. 1-3). Further workup including CSF examination revealed positive IgG bands and negative oligoclonal bands. Also autoimmune serology results, including anti-JO and lupus, ANCA, anti-CCP, and anti-smooth muscle antibodies, were negative, while ANA and anti-RO were positive, but there was no supportive clinical evidence of other forms of vasculitis or connective tissue diseases. In reference to the new diagnosis, the patient was managed with pulse steroid $1 \mathrm{~g}$ daily for 5 days followed by 5 sessions of plasma exchange, with no significant improvement, and she was maintained on azathioprine.

During the next 7 years, she had a stable course regarding motor power of her limbs, but she had recurrent attacks of right optic neuritis, for which she received many courses of intravenous methylprednisolone (IVMP) for 3-5 days. At the age of 36 years, she developed a sudden-onset headache with normal blood pressure, and her CT and MRI confirmed a rim of subarachnoid hemorrhage (SAH) in the left frontal cortical sulci (Fig. 4a, b), while CT angiography and MR venography (Fig. 4c) excluded arteriovenous malformations or aneurysms.

The patient was managed conservatively, and repeated CT after 6 months indicated the resolution of the SAH (Fig. 5). With continuation of relapses of visual affection in the right eye, the patient was started on rituximab 2 months back and received 2 doses with no significant clinical improvement. Currently, the patient is bedridden with spastic paraplegia and a blind left eye.

\section{Literature Review}

Regarding cerebral hemorrhage in patients with NMO, apart from our case, a literature review revealed only 3 previous case reports and a fourth case of hemorrhagic encephalitis. The first case was described by Shirai et al. [3], who reported on a 48-year-old man who was admitted because of intractable hiccups, nausea, and orthostatic hypotension, and who then developed respiratory failure. Brain MRI showed SAH in addition to enlarged medullary lesions with positive serum anti-AQP4 antibody.

The second case was described by Yaguchi et al. [4], who reported on a woman without hypertension who had previously experienced intracranial hemorrhage twice, at 48 and 56

\section{Karger'=}




\section{Case Reports in Neurology}

Case Rep Neurol 2021;13:157-165

DOI: $10.1159 / 000513644$

2021 The Author(s). Published by S. Karger AG, Basel www.karger.com/crn

Elshony et al.: Intracerebral Hemorrhage in Patients with Neuromyelitis Optica

years of age, after which she was diagnosed with NMOSD at the age of 59 years based on the presence of a brain stem lesion and the detection of anti-AQP4 antibodies.

Most recently, the third case was described by Kamo et al. [5], who reported on a 51-yearold Japanese woman with a history of hypertension and dyslipidemia and recurrent episodes of left visual acuity disorder related to AQP4-positive NMOSD. She developed blindness in the left eye, and brain MRI showed a hyperintense lesion in her pons, so she was initially diagnosed with recurrence of NMOSD and 1,000 mg of IVMP was administered for 3 days. After the third course of IVMP, she developed left-sided sensory disturbance, and the blood pressure had increased to 202/127 mm Hg; brain CT showed pontine hemorrhage. She was diagnosed with posterior reversible encephalopathy syndrome associated with NMOSD recurrence, along with development of pontine hemorrhage induced by the increase in blood pressure resulting from IVMP.

In April 2019, Du et al. [6] reported on a case of a patient with NMO who presented with hemorrhagic encephalitis during the course of the disease.

\section{Discussion}

While the pathogenesis of NMO is not fully understood, it is believed that AQP4-IgG is of great importance in triggering the pathology of the disease. AQP4 is a transmembrane protein expressed by astrocytes and controls the flow of water in cells [7]. Upon penetration through the blood-brain barrier (BBB) and binding with AQP4 on perivascular astrocyte end-feet, AQP4-IgG activates the classic complement pathway which causes astrocyte damage, followed by marked NK cell, granulocyte and monocyte infiltration, along with BBB breakdown, oligodendrocyte death and demyelination, microglia activation, and even neuronal apoptosis [8]. Thus, in the CNS, AQP4 immunoreactivity is expressed around the capillary blood vessels and foot processes of astrocytes beneath the pia mater, and serum from NMO patients disrupts the BBB [9]. Unfortunately, the mechanism of AQP4-IgG generation remains unclear; predictions include AQP4 molecular mimicry and infection $[10,11]$. Th17 cells and follicular helper T cells [12] significantly increase during the relapse period, which are critical for breaking down the BBB and antibody production.

\section{Link between NMO and Vascular Pathology}

A study involving 31 NMO patients found various Th2-related cytokines such as interleukin (IL)-1 receptor antagonist, IL-5, IL-10, and IL-13, as well as the Th17-related cytokines IL6, IL-8, and granulocyte colony-stimulating factor, to be elevated in the CSF [13]. Epidemiological studies have found an increased vascular risk in association with increased basal levels of cytokines such as IL- 6 and tumor necrosis factor- $\alpha$.

Tumor necrosis factor- $\alpha$ is an important cytokine in the injured vasculature, where it may function to regulate the expression of platelet-derived growth factor, vascular endothelial growth factor, fibroblast growth factor, adhesion molecules, cytokines, and extracellular matrix (ECM)-degrading matrix metalloproteinases, as well as directly affecting vascular smooth muscle cell growth and migration. Other cytokines such as IL-1 $\beta$ and IL- 6 contribute to the pathogenesis of specific vascular diseases [14]. Thus, these cytokines induce vascular cell growth and migration, induce apoptosis, promote adhesion of immune cells to endothelial cells (ECs), and cause an increase in vascular permeability [15]. Many of the effects of cytokines on vascular cells could also involve increases in reactive oxygen species, which in high

\section{Karger'=}




\section{Case Reports in Neurology}

\begin{tabular}{l|l}
\hline Case Rep Neurol 2021;13:157-165 \\
\hline DOI: 10.1159/000513644 & $\begin{array}{l}\text { @ 2021 The Author(s). Published by S. Karger AG, Basel } \\
\text { www.karger.com/crn }\end{array}$ \\
\hline
\end{tabular}

Elshony et al.: Intracerebral Hemorrhage in Patients with Neuromyelitis Optica

concentrations cause cellular injury and death. ECs are a major target of oxidative stress, which plays a critical role in the pathophysiology of vascular disease. Cytokines may have additional specific effects on the vascular ECs, vascular smooth muscles, and ECM. Such effects could affect the mechanism of vascular tone and the signaling pathways of vasoconstriction and vasodilation, as well as vascular cell growth and proliferation, and could also lead to structural changes in vessel wall architecture and the ECM [16].

Evidence of Vascular Pathology in NMO

Data regarding (1) the presence of these cytokines in NMO patients [13], (2) the earliest pathological descriptions of NMO which highlighted the frequent occurrence of necrosis with cavitation, hyalinization of small vessels, and perivascular inflammatory infiltrates which distinguish NMO from multiple sclerosis, and (3) also the more recent work which has indicated the importance of perivascular deposition of immunoglobulin and complement [17] and its localization to the vascular glial limiting membrane [18], with infiltrate consisting of macrophages, granulocytes, and eosinophils with a general paucity of lymphocytes [19], all confirm the vascular pathology that occurs in NMO, resulting in fragile blood vessels which might cause SAH. Also, modern histopathological techniques have demonstrated the specificity of acute fragmentation and loss of perivascular GFAP-positive astrocyte foot processes and their cell bodies as an early and consistent feature of NMO [20, 21]. These mechanisms could explain the possibility of occurrence of many types of vascular disorder in NMO patients, predisposing them to the hemorrhage observed in our cases.

\section{Conclusions}

An association between NMO and cerebral hemorrhage could be suggested in the context of our understanding of NMO pathology and the role of the different cytokines in the disease pathogenesis. We believe that further research is needed to confirm the relation between $\mathrm{NMO}$ and the development of vascular disorders.

\section{Statement of Ethics}

Written informed consent was obtained from the patient for publication of this case report and any accompanying images.

\section{Conflict of Interest Statement}

The authors have no conflicts of interest to declare.

\section{Funding Sources}

No funding was received from any governmental or nongovernmental sources.

\section{Karger'}




\section{Case Reports in Neurology}

Case Rep Neurol 2021;13:157-165

DOI: $10.1159 / 000513644$

(c) 2021 The Author(s). Published by S. Karger AG, Basel www.karger.com/crn

\section{Author Contributions}

H.S. Elshony: study design, manuscript writing, literature review, and editing. A. Idris: manuscript reviewing and editing. A. Al-Ghamdi: manuscript reviewing and editing. R. Muddassir: literature review and manuscript writing.

\section{References}

1 Wingerchuk DM, Lennon VA, Lucchinetti CF, Pittock SJ, Weinshenker BG. The spectrum of neuromyelitis optica. Lancet Neurol. 2007 Sep;6(9):805-15.

2 Correale J, Fiol M. Activation of humoral immunity and eosinophils in neuromyelitis optica. Neurology. 2004 Dec;63(12):2363-70.

3 Shirai S, Mito Y, Nojo T, Yaguchi H, Takahashi T, Sato K, et al. Neuromyelitis optica spectrum disorders accompanying subarachnoid hemorrhage and reversible white matter lesions. Neurol Clin Neurosci. 2014;2(1):10-2.

4 Yaguchi H, Mito Y, Ohashi I, Nomura T, Yabe I, Tajima Y. Neuromyelitis Optica Spectrum Disorder with Recurrent Intracranial Hemorrhage. Intern Med. 2017;56(13):1729-32.

5 Kamo H, Ueno Y, Sugiyama M, Miyamoto N, Yamashiro K, Tanaka R, et al. Pontine hemorrhage accompanied by neuromyelitis optica spectrum disorder. J Neuroimmunol. 2019 May;330:19-22.

6 Du Q, Chen H, Shi Z, Zhang Y, Wang J, Zhou H. Hemorrhagic encephalitis in a patient with neuromyelitis optica: a case report. J Spinal Cord Med. 2019 [Online ahead of print].

7 Agre P, Kozono D. Aquaporin water channels: molecular mechanisms for human diseases. FEBS Lett. 2003 Nov;555(1):72-8.

8 Papadopoulos MC, Verkman AS. Aquaporin 4 and neuromyelitis optica. Lancet Neurol. 2012 Jun;11(6):53544.

9 Lucchinetti CF, Guo Y, Popescu BF, Fujihara K, Itoyama Y, Misu T. The pathology of an autoimmune astrocytopathy: lessons learned from neuromyelitis optica. Brain Pathol. 2014 Jan;24(1):83-97.

10 Varrin-Doyer M, Spencer CM, Schulze-Topphoff U, Nelson PA, Stroud RM, Cree BA, et al. Aquaporin 4-specific T cells in neuromyelitis optica exhibit a Th17 bias and recognize Clostridium ABC transporter. Ann Neurol. 2012 Jul;72(1):53-64.

11 Koga M, Takahashi T, Kawai M, Fujihara K, Kanda T. A serological analysis of viral and bacterial infections associated with neuromyelitis optica. J Neurol Sci. 2011 Jan;300(1-2):19-22.

12 Li YJ, Zhang F, Qi Y, Chang GQ, Fu Y, Su L, et al. Association of circulating follicular helper T cells with disease course of NMO spectrum disorders. J Neuroimmunol. 2015 Jan;278:239-46.

13 Uzawa A, Mori M, Arai K, Sato Y, Hayakawa S, Masuda S, et al. Cytokine and chemokine profiles in neuromyelitis optica: significance of interleukin-6. Mult Scler. 2010 Dec;16(12):1443-52.

14 Ridker PM, Hennekens CH, Buring JE, Rifai N. C-reactive protein and other markers of inflammation in the prediction of cardiovascular disease in women. N Engl J Med. 2000 Mar;342(12):836-43.

15 Paria BC, Vogel SM, Ahmmed GU, Alamgir S, Shroff J, Malik AB, et al. Tumor necrosis factor-alpha-induced TRPC1 expression amplifies store-operated Ca2+ influx and endothelial permeability. Am J Physiol Lung Cell Mol Physiol. 2004 Dec;287(6):L1303-13.

16 Griendling KK, Sorescu D, Lassègue B, Ushio-Fukai M. Modulation of protein kinase activity and gene expression by reactive oxygen species and their role in vascular physiology and pathophysiology. Arterioscler Thromb Vasc Biol. 2000 Oct;20(10):2175-83.

17 Lucchinetti CF, Mandler RN, McGavern D, Bruck W, Gleich G, Ransohoff RM, et al. A role for humoral mechanisms in the pathogenesis of Devic's neuromyelitis optica. Brain. 2002 Jul;125(Pt 7):1450-61.

18 Barnett MH, Parratt JD, Cho ES, Prineas JW. Immunoglobulins and complement in postmortem multiple sclerosis tissue. Ann Neurol. 2009 Jan;65(1):32-46.

19 Mandler RN, Davis LE, Jeffery DR, Kornfeld M. Devic's neuromyelitis optica: a clinicopathological study of 8 patients. Ann Neurol. 1993 Aug;34(2):162-8.

20 Parratt JD, Prineas JW. Neuromyelitis optica: a demyelinating disease characterized by acute destruction and regeneration of perivascular astrocytes. Mult Scler. 2010 Oct;16(10):1156-72.

21 Barnett MH, Prineas JW, Buckland ME, Parratt JD, Pollard JD. Massive astrocyte destruction in neuromyelitis optica despite natalizumab therapy. Mult Scler. 2012 Jan;18(1):108-12. 
Case Reports in Neurology
Case Rep Neurol 2021;13:157-165

DOI: $10.1159 / 000513644$ (c) 202 www.karger.com/crn

Elshony et al.: Intracerebral Hemorrhage in Patients with Neuromyelitis Optica
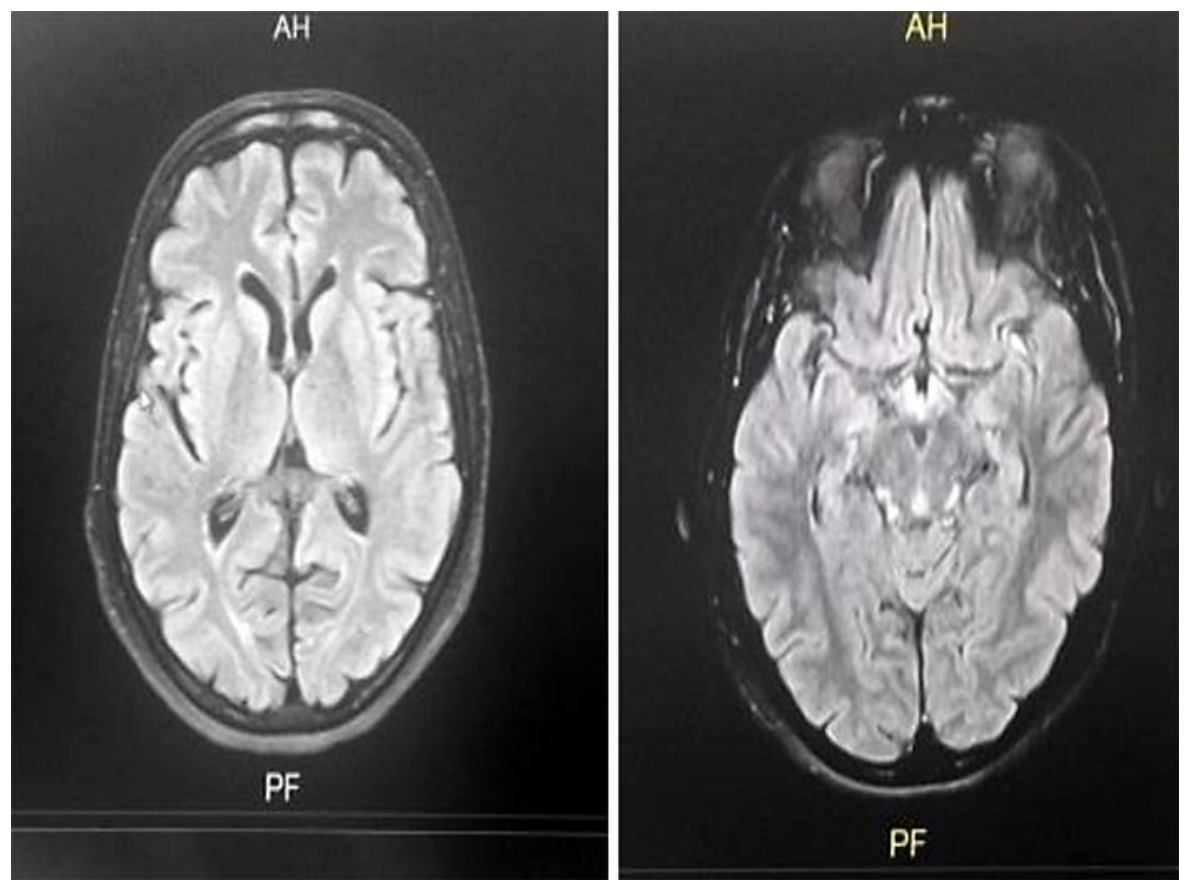

Fig. 1. Axial FLAIR MRI showing no supra- or infratentorial areas/foci of abnormal signals.

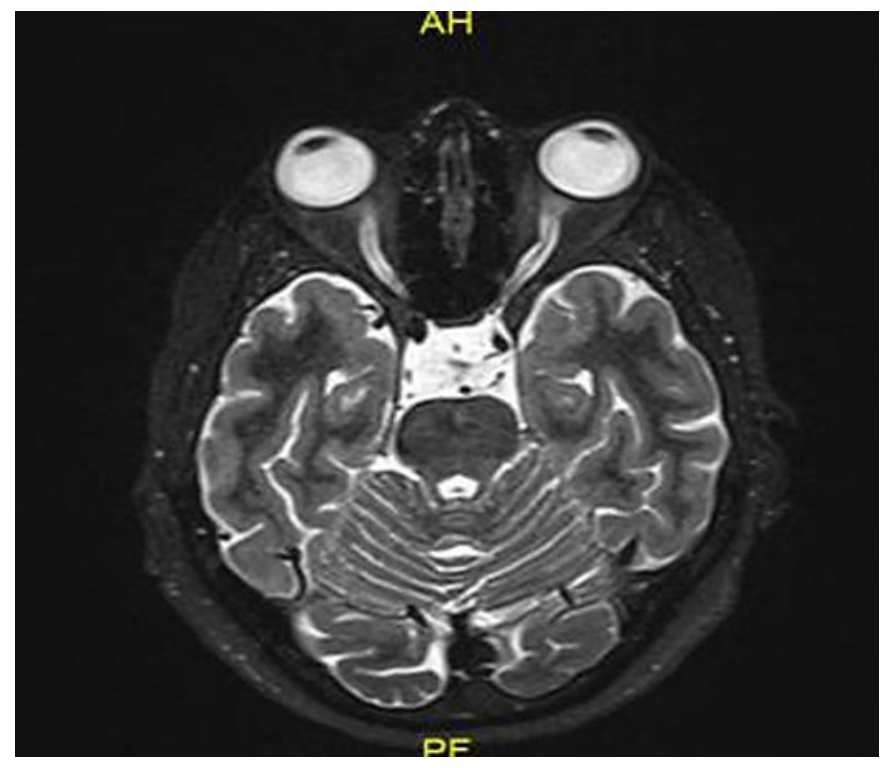

Fig. 2. Axial high-resolution T2-weighted MRI showing atrophic changes affecting the optic nerve bilaterally, with prominent CSF in the optic sheath, with no infratentorial abnormal signal intensity. 
Case Reports in Neurology
Case Rep Neurol 2021;13:157-165

DOI: $10.1159 / 000513644$

(c) 2021 The Author(s). Published by S. Karger AG, Basel www.karger.com/crn

Elshony et al.: Intracerebral Hemorrhage in Patients with Neuromyelitis Optica
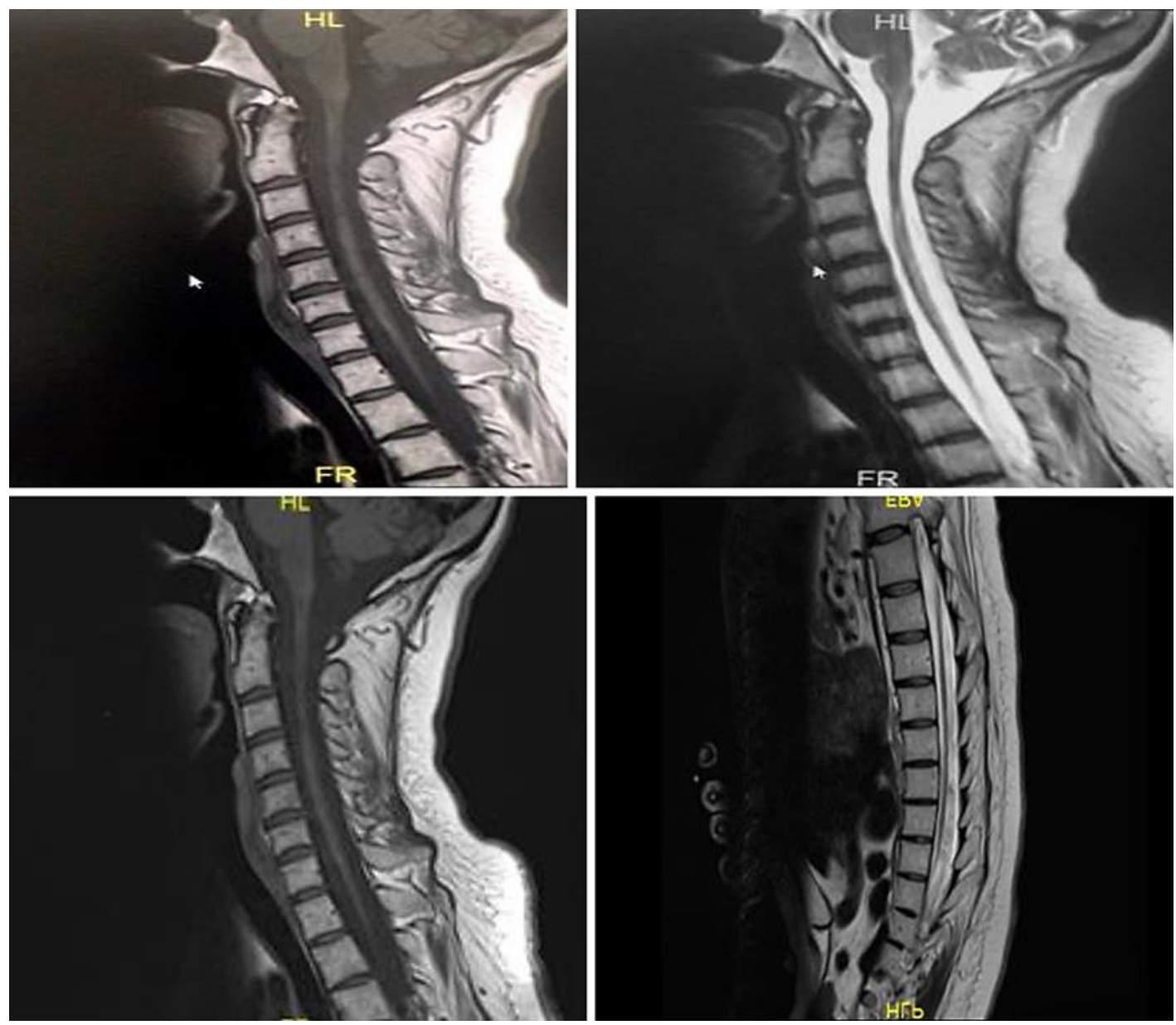

Fig. 3. Sagittal T1-, T2-, T1-weighted post-gadolinium-enhanced cervical MRI and sagittal T2-weighted dorsal MRI showing atrophic changes with prominent CSF with no areas of abnormal signal intensity. 
Case Reports in Neurology
Case Rep Neurol 2021;13:157-165

DOI: $10.1159 / 000513644$

(c) 2021 The Author(s). Published by S. Karger AG, Basel www.karger.com/crn
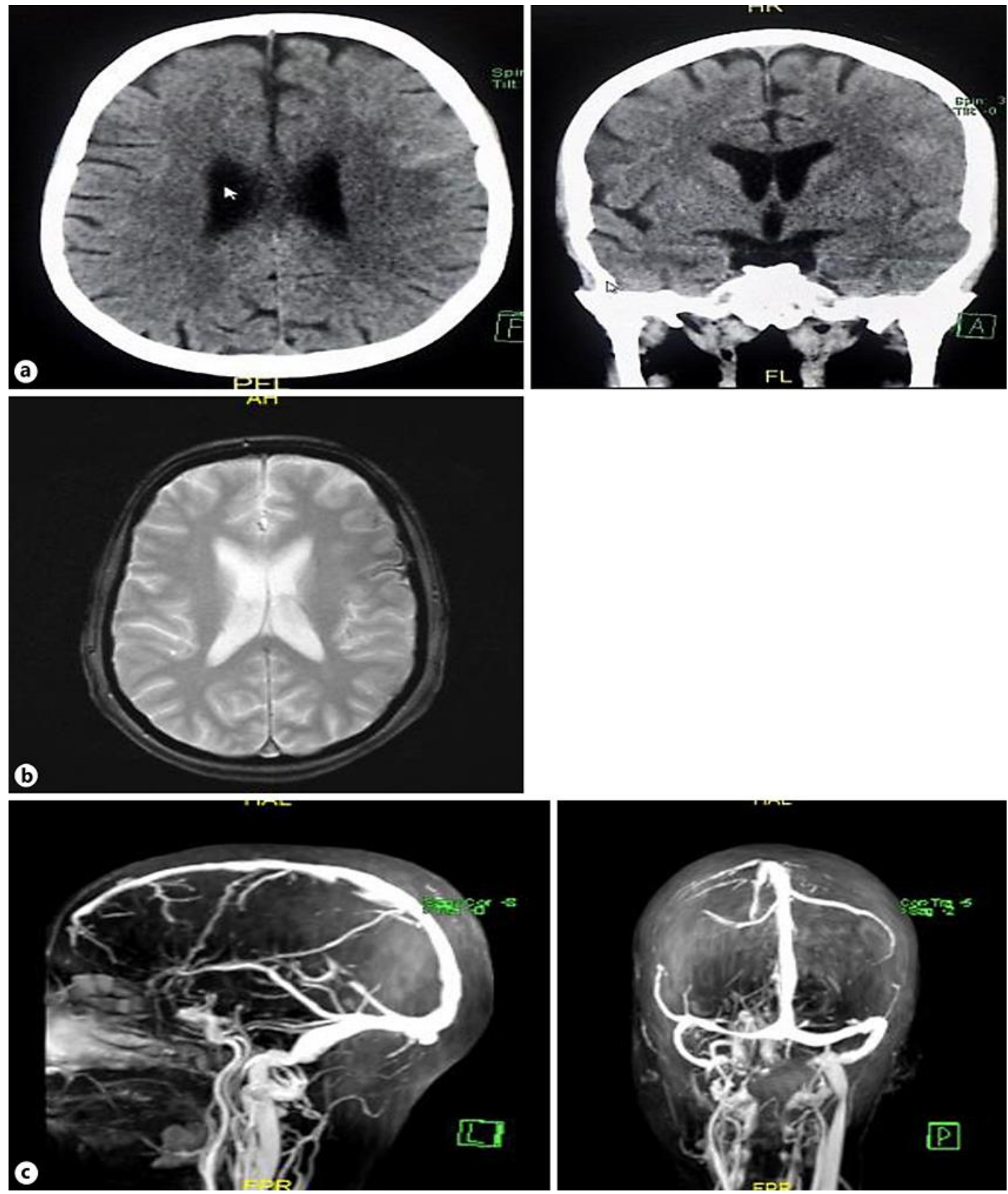

Fig. 4. a Axial and coronal noncontrast CT done at the onset of the headache showing high-density blood involving the left cortical sulci (subarachnoid hemorrhage [SAH]). b Brain axial gradient MRI showing blooming of the left frontal cortical sulci confirming the diagnosis of SAH. c Sagittal and coronal brain MR venography, axial view, showing no filling defect or thrombosed veins. 
Case Reports in Neurology
Case Rep Neurol 2021;13:157-165 DOI: $10.1159 / 000513644$

(c) 2021 The Author(s). Published by S. Karger AG, Basel www.karger.com/crn

Elshony et al.: Intracerebral Hemorrhage in Patients with Neuromyelitis Optica
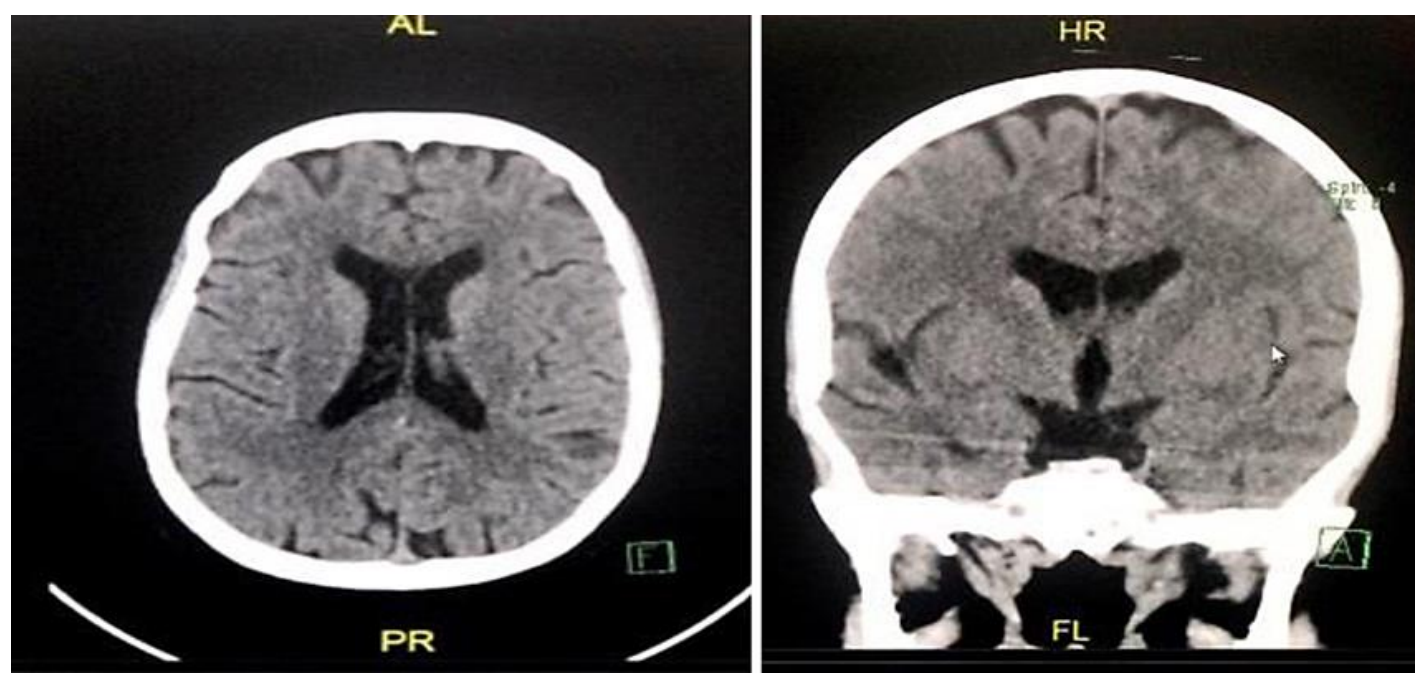

Fig. 5. Axial and coronal noncontrast CT done 6 months after the onset of subarachnoid hemorrhage showing complete resolution of the hemorrhage. 